\title{
Reduction in Sharpness of Frequency Tuning but not Endocochlear Potential in Aging and Noise-Exposed BALB/cJ Mice
}

\author{
Kevin K. Ohlemiller \\ Fay and Carl Simons Center for the Biology of Hearing and Deafness, Central Institute for the Deaf, Saint Louis, \\ MO 63110, USA
}

Received: 23 August 2001; Accepted: 5 February 2002; Online publication: 9 April 2002

\section{ABSTRACT}

Schuknecht proposed categories for human age-related hearing loss (ARHL) based upon whether the primary degeneration involves the organ of Corti (sensory ARHL), spiral ganglion cells (neural), stria vascularis (strial), or a combination of these (mixed). Genetically standardized mouse ARHL models can help validate Schuknecht's framework and clarify the underlying cellular processes. Much recent work has focused on the mouse $A h l$ locus, which promotes both ARHL and noise-induced hearing loss. On the C57BL/ 6 inbred background, $A h l$ has been associated with degeneration of organ of Corti, afferent neurons, and stria vascularis/spiral ligament, suggesting that it promotes mixed (sensory/neural/strial) ARHL. Some cochlear degeneration in C57BL/6 mice could be caused by genes other than $A h l$, however. The question of what constitutes Ahl-related pathology can be addressed by comparing C57BL/6 mice with other strains that carry the same allele, including BALB/c substrains. We examined the effects of aging and broadband noise exposure in inbred BALB/cJ mice (1.5-13.0 mos) using measures of frequency tuning (compound action potential tuning curves) (CAPTCs), strial function (endocochlear potential recording, EP), and light microscopy. Aging and noise led to generally similar physiological and anatomical changes. Reductions in sensitivity and sharp-

Correspondence to: Kevin K. Ohlemiller, Ph.D. - Research Department - Central Institute for the Deaf -4560 Clayton Ave. - St. Louis, MO 63110. Telephone: (314) 977-0279; fax: (314) 977-0030; email: kohlemiller@cid.wustl.edu ness of frequency tuning were not consistently linked to hair cell loss, reduction in the EP, or changes in the lateral wall. Instead they appeared best explained by alterations in supporting cells in the basal half of the cochlear and in the spiral limbus in the apex. These results emphasize the importance of cell types other than hair cells in cochlear pathology. They also indicate that $A h l$ does not necessarily promote a strial form of ARHL.

Keywords: cochlea, hair cells, stria vascularis, spiral limbus, presbycusis, Ahl, mdfw

\section{INTRODUCTION}

Sensorineural age-related hearing loss (ARHL, or presbycusis) appears in over $40 \%$ of people by age 65 (National Center for Health Statistics 1994), and thus is the major neurodegenerative disease of aging. Its causes remain poorly understood because of the difficulty of separating genetic and environmental contributors (Schuknecht 1974; Willott 1991; Li 1992b). Schuknecht (1974; Schuknecht and Gacek 1993) proposed categories for human ARHL, defined according to the degeneration that best accounted for the observed hearing performance. In the majority of cases $(\sim 60 \%)$, overall hearing ability appeared best explained by degeneration of organ of Corti (sensory ARHL), spiral ganglion cells (neural), stria vascularis (strial), or a combination of these (mixed). Often, the audiometric pattern appeared attributable to principally one structure, leading Schuknecht to speculate that sensory, neural, and strial ARHL categories are 
causally or genetically distinct. However, cases in which degeneration of multiple cell types met Schuknecht's criteria occurred more often than would be predicted from their conditional probabilities. This suggests that a single factor may underlie some mixed ARHL.

Animal models of ARHL can help to clarify Schuknecht's framework and its genetic foundations. In comparisons of the effects of aging across species, Schuknecht's categories may emerge and ultimately facilitate identification of genes that promote ARHL and their human homologs. Mouse models of ARHL are popular because of the short life span, genetic standardization, and increasingly detailed genetic characterization of laboratory mice. Several inbred strains show progressive sensorineural hearing loss by a few months of age (Mikaelian 1979; Henry 1983; Erway et al. 1993; Li and Hultcrantz 1994; Saitoh et al. 1994; Parham 1997; Willott et al. 1998; Zheng et al. 1999) and have been proffered as phenotypic, mechanistic, and genetic models of human ARHL. The mouse ARHL models examined in greatest detail thus far (C57BL/6- and BALB/c-related strains, and the SAMP1 mouse) appear to fall into Schuknecht's mixed ARHL category. Cochlear degeneration in these models begins early in adulthood and includes hair cell loss and primary neuronal loss (Henry 1983; Saitoh et al. 1995; Spongr et al. 1997; Willott et al. 1998). Degeneration of stria vascularis and spiral ligament may eventually follow (Saitoh et al. 1995; Ichimiya et al. 2000; Hequembourg and Liberman 2001).

C57BL/6- and BALB/c-related strains (henceforth C57BL/ 6 and BALB/c) are homozygous for $A h l$ (Johnson et al. 1997, 2000), which imparts both vulnerability to noise and ARHL (Henry 1982; Li 1992a; Erway et al. 1996; Ohlemiller et al. 2000b; Davis et al. 2001; Jimenez et al. 2001). Ahl may therefore exemplify a single locus that can promote mixed ARHL through a susceptibility mechanism (Li 1992b; Ohlemiller et al. 2000a). Recent evidence indicates that $A h l$ is allelic with $m d f w$ and Waltzer $(C d h 23 v)$ and that the product of this locus is cadherin 23, which is present in hair cells (Bryda et al. 2001; Di Palma et al. 2001; Wilson et al. 2001). Early disruption of the hair cell stereociliary bundle in Waltzer mutant mice (Di Palma et al. 2001) may account for their hair cell loss (Steel 1995), and $A h l$ may impair long-term hair cell survival through a related mechanism. However, neither primary neuronal loss (that is, occuring prior to hair cell loss) nor degeneration of the lateral wall are predicted.

Because of Ahl's potential value for testing Schuknecht's framework and elucidating how mixed ARHL may arise, it is important to determine what cochlear pathology is actually attributable to this mutation. Degeneration tentatively attributed to $A h l$ in any inbred strain may actually result from alleles of other genes in the genetic background. Fortunately, C57BL/ 6 and BALB/c mice, plus at least seven additional inbred strains, are believed to carry the same $A h l$ allele (Johnson et al. 2000; Zheng and Johnson 2001). The issue of Ahl-related pathology can be explored elegantly by intercrosses and backcrosses, or more conveniently by detailed comparison of these inbred strains. We chose the latter approach and have begun by extending previous work in BALB/c mice (Willott et al. 1998; Jimenez et al. 1999, 2001; Ohlemiller et al. 2000b). Our underlying assumption is that shared aspects of cochlear pathology are likely to be those most strongly linked to $A h l$. Although studies indicate that both C57BL/6 and BALB/c mice show hair cell loss and primary neuronal loss (Spongr et al. 1997; Willott et al. 1998; Hequembourg and Liberman 2001), whether they share pathology of stria and spiral ligament is not well established. Willott et al. (1998) reported that stria vascularis appears normal in aging $\mathrm{BALB} / \mathrm{c}$ mice, while abnormalities of the stria/spiral ligament in C57BL/6 and closely related strains have been repeatedly described (Mikaelian 1979; Ichimiya et al. 2000; Hequembourg and Liberman 2001). We evaluated cochleas of BALB/cJ mice that varied in age $(1.5-13.0 \mathrm{mos})$ and noise history. Cochlear function was evaluated by round window compound action potential (CAP) recording, hair cell counts, and conventional light microscopy. CAP tuning curves (CAPTCs), which permitted assessment of the impact of aging and noise on frequency tuning, were obtained using a $20 \mathrm{kHz}$ probe. Strial function and the integrity of scala media were assessed by measuring the endocochlear potential (EP) in the lower basal turn.

\section{MATERIALS AND METHODS}

Animals

All procedures were approved by the CID Animal Care and Use Committee. The study included 70 male and female BALB/cJ mice (1.5-13.0 mos), and 7 male and female CBA/CaJ mice (henceforth CBA/ Ca) (2 mos). All animals were descended from mating pairs obtained from The Jackson Laboratory and were raised in the CID vivarium.

\section{Noise exposure}

Ten mice near 3 months of age were exposed to broadband noise. Noise exposures were performed in a foam-lined, double-walled soundproof room (Industrial Acoustics). The noise exposure apparatus consisted of a $21 \times 21 \times 11 \mathrm{~cm}$ wire cage mounted on a pedestal inserted into a B\&K 3921 turntable. To 
ensure a uniform sound field, the cage was rotated at 1 revolution/80 s within a $42 \times 42 \mathrm{~cm}$ metal frame. Motorola KSN1020A piezo ceramic speakers (four total) were attached to each side of the frame. Opposing speakers were oriented nonconcentrically, parallel to the cage, and driven by separate channels of a Crown D150A power amplifier. Noise was generated by General Radio 1310 generators and bandpassed at $4.0-45.0 \mathrm{kHz}$ by Krohn-Hite 3550 filters. The overall noise level was measured at the center of the cage using a B\&K $4135 \quad 1 / 4$ in. microphone in combination with a B\&K 2231 sound level meter. Noise spectrum level was determined using a Hewlett Packard 3581A wave analyzer set at $300 \mathrm{~Hz}$ bandwidth and is shown elsewhere (Ohlemiller et al. 1999). Mice were exposed in pairs for $7.5 \mathrm{~min}$ at $110 \mathrm{~dB}$ SPL, which duration and level we have shown to reliably cause noise-induced hearing loss (NIHL) in BALB/c (Ohlemiller et al. 2000b). Morphometric data have also been included (Fig. 12) from 10 animals from our previous study that were noise-exposed for durations ranging from 0.5 to $7.5 \mathrm{~min}$ and evaluated by ABR recording.

\section{CAP recording}

CAP recordings were performed 2-3 weeks following noise exposure. Animals were anesthetized $(60 \mathrm{mg} /$ $\mathrm{kg}$ sodium pentobarbital, IP) and positioned ventrally in a custom headholder. Core temperature was maintained at $37.5 \pm 1.0^{\circ} \mathrm{C}$ using a thermostatically controlled heating pad in conjunction with a rectal probe (Yellow Springs Instruments Model 73A). An incision was made along the midline of the neck and soft tissues were blunt-dissected and displaced laterally to expose the trachea and animal's left bulla. A tracheostomy was then made and the musculature over the bulla was cut posteriorly to expose the bone overlying the round window. Using a hand drill, a small hole was made over the round window. The recording electrode was a modified platinum needle electrode (Grass) insulated with epoxy, except for the tip, which was inserted into the round window antrum using a micromanipulator. Additional platinum electrodes inserted into the neck musculature and hind leg served as reference and ground, respectively. Electrodes were led to a Grass P15 differential amplifier $(100-3000 \mathrm{~Hz}, \times 100)$, then to a custom amplifier providing another $\times 1000$ gain, then digitized at $30 \mathrm{kHz}$ using a Cambridge Electronic Design Micro 1401 in conjunction with SIGNAL $^{\mathrm{TM}}$ (Cambridge Electronic Design) and custom signal-averaging software operating on a 120 $\mathrm{MHz}$ Pentium PC. Sine wave stimuli generated by a Hewlett Packard 3325A oscillator were shaped by a custom electronic switch to $5 \mathrm{~ms}$ total duration, including $1 \mathrm{~ms}$ rise/fall times. The stimulus was amplified by a Crown D150A power amplifier and output to a KSN1020A piezo ceramic speaker located $7 \mathrm{~cm}$ directly lateral to the left ear. Stimuli were presented freefield and calibrated using a B\&K 4135 $1 / 4$ in. microphone placed where the external auditory meatus would normally be. Tone burst stimuli at each frequency and level were presented 100 times at $3 / \mathrm{s}$. The minimum sound pressure level required for visual detection of a response $\left(N_{\mathrm{i}}\right)$ was determined at $5,10,20,28.3$, and $40 \mathrm{kHz}$ using a $5 \mathrm{~dB}$ minimum step size.

\section{Derivation of CAP tuning curves}

To obtain CAPTCs, a $20 \mathrm{kHz}$ probe presented 100 times at $3 / \mathrm{s}$, at a level of $5 \mathrm{~dB}$ above $N_{1}$ visual detection threshold, was passively mixed with a calibrated ungated masking tone. The masker was generated by a second Hewlett Packard 3325A oscillator. The masker was varied in frequency and amplitude to determine the set of minimum masker levels that would reliably extinguish $N_{\mathrm{i}}$. We chose the $20 \mathrm{kHz}$ region of the cochlea for testing because this region is readily affected by noise and aging in $\mathrm{BALB} / \mathrm{c}$ mice and because $20 \mathrm{kHz}$ lies near the peak sensitivity of the mouse audiogram. CAP tuning curves were sampled in $10 \%$ frequency increments near the tip of the curve and 20\% increments in the "tail." Sharpness of tuning was quantified by calculating the $Q_{20}$, which expresses the ratio of best frequency (probe frequency) to the bandwidth of the tuning curve $20 \mathrm{~dB}$ above minimum threshold. $Q_{20}$ is less often applied than is $Q_{10}$ However, based on our experience with single auditory neurons (Ohlemiller and Siegel 1994), it is more sensitive and less variable as a measure of sharpness of tuning than $Q_{10}$. In cases where aging or noise exposure decreased CAPTC tip length to less than $20 \mathrm{~dB}, Q_{20}$ was assigned a value of 0.0 for illustration.

\section{Endocochlear potential recording}

EP measures were obtained immediately after CAP recording. A hole in the left cochlear capsule was made using a fine drill at a position we estimate typically corresponded to the $20-30 \mathrm{kHz}$ region, based on the cochlear frequency map for mouse $(\mathrm{Ou}$ et al. $2000 \mathrm{~b})$. Glass capillary pipettes $(40-80 \mathrm{M} \Omega$ ) filled with $0.15 \mathrm{M} \mathrm{KCl}$ were mounted on a hydraulic microdrive (Frederick Haer) and advanced until a stable positive potential was observed that did not change with increased electrode depth. The signal from the recording electrode was led to an AM Systems Model 1600 intracellular amplifier. 


\section{Histology}

At the end of recording, animals were overdosed and perfused transcardially with cold $2.0 \%$ paraformaldehyde $/ 2.0 \%$ glutaraldehyde in $0.1 \mathrm{M}$ phosphate buffer. Each cochlea was rapidly isolated, immersed in the same fixative, and the stapes was immediately removed. Complete infiltration of the cochlea by fixative was ensured by making a small hole at the apex of the cochlear capsule and gently circulating the fixative over the cochlea using a transfer pipette. After decalcification in sodium EDTA, cochleas were postfixed in buffered 1\% osmium tetroxide, dehydrated in an ascending acetone series, and embedded in Epon.

Twelve right cochleas were prepared for hair cell counts by dissection of embedded cochleas into roughly half-turn segments, shaving each piece as close as possible to the basilar membrane and viewing with pieces immersed in mineral oil under Nomarski optics using a calibrated ocular. Hair cell counts reported here covered only the region of the cochlea spanning 1.8-2.2 $\mathrm{mm}$ from the basal tip, that is, a span that presumably includes the $20 \mathrm{kHz}$ region according to the cochlear frequency map for mouse (Ou et al. 2000b). Hair cells were counted in three nonoverlapping $100 \mu \mathrm{m}$ segments. Animals chosen for counts were those that showed very different frequency tuning at $20 \mathrm{kHz}$, specifically those with $Q_{20}$ $<2.0$ and $>5.0$. The same basal region in eight of the cochleas used for cell counts were then further dissected into wedges for radial sectioning at $1.0 \mu \mathrm{m}$. The left cochleas from the same animals, plus four additional animals $(n=16)$, were sectioned in the midmodiolar plane at 2.0 or $4.0 \mu \mathrm{m}$.

\section{RESULTS}

Effects of aging on sensitivity and frequency tuning

CAP thresholds obtained at ages ranging from 1.5 to 13.0 mos revealed an early and rapidly progressing hearing loss, particularly at high frequencies. Figure 1 shows mean thresholds for animals in four age groups. Even for ages less than $2.5 \mathrm{mos}, \mathrm{BALB} / \mathrm{c}$ mice were slightly less sensitive than similar-aged $\mathrm{CBA} / \mathrm{Ca}$ mice and high-frequency hearing loss was already evident. CAP thresholds at $20 \mathrm{kHz}$ increased with age, although most of the increase occurred after 6 months (Fig. 2). Thresholds exceeded $60 \mathrm{~dB}$ SPL by one year.

CAP tuning curves in young $\mathrm{CBA} / \mathrm{Ca}$ and $\mathrm{BALB} / \mathrm{c}$ mice (Fig. 3A, B) showed clear tips and tails characteristic of auditory neurons in mammals. $Q_{20 \mathrm{~s}}$ of CAPTCs obtained using a $20 \mathrm{kHz}$ probe ranged from

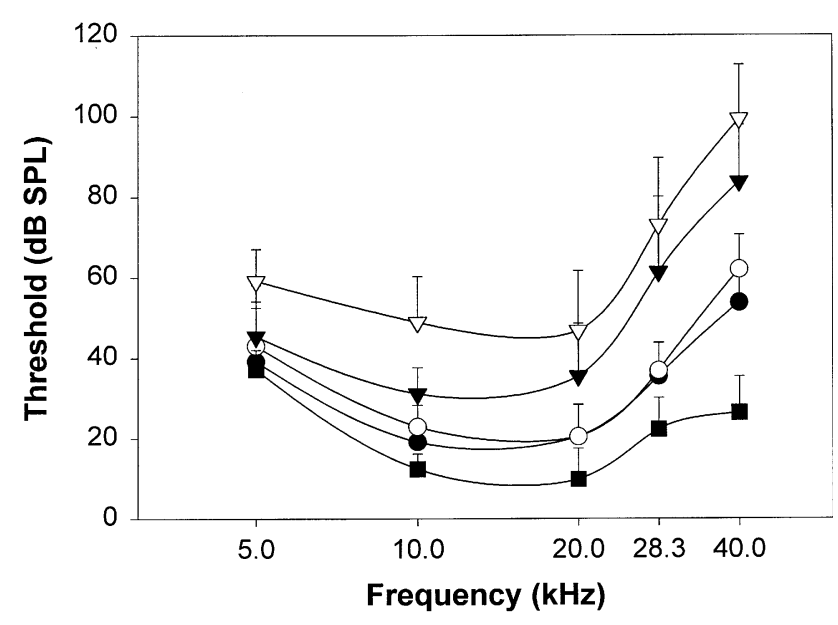

FIG. 1. Mean $(+\mathrm{SD})$ CAP thresholds in BALB/C mice varying from 1.5 to 13.0 months in age, assigned to four age brackets. Comparison data from young $\mathrm{CBA} / \mathrm{CaJ}$ mice are also shown. (-) BALB/C 1.5-2.5 mos, (○) BALB/c 4-6 mos, ( $)$ BALB/c 7.5-9 mos, ( $\nabla)$ BALB/c 10.513 mos, (ם) CBA/Ca 2 mos.

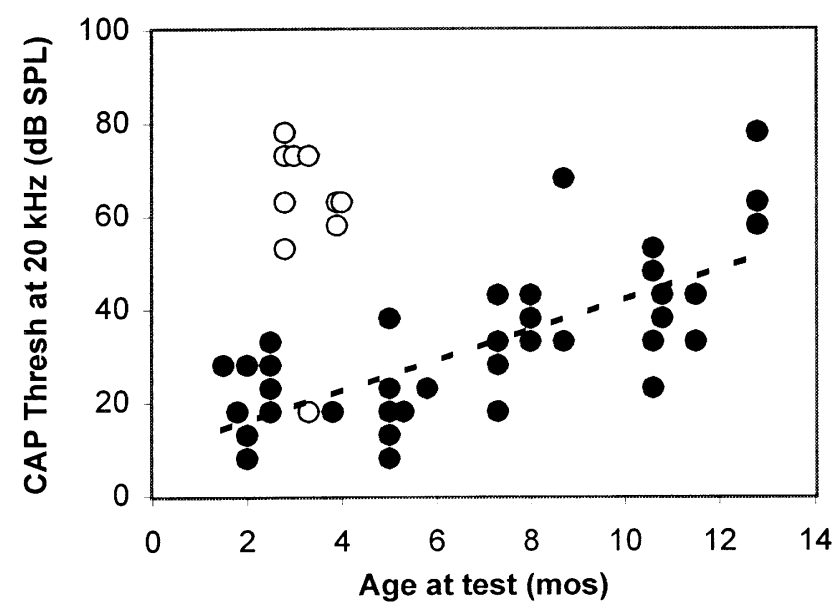

FIG. 2. Scatter plot of CAP thresholds at $20 \mathrm{kHz}$ versus age of testing in BALB/c mice. Thresholds are increased above 6 months of age and progressively rise thereafter (Pearson correlation $r=0.74$; $p<0.001)$. Thresholds for young BALB/c mice exposed to noise are also shown $(\bigcirc)$.

$\sim 4.0$ to 8.0 in the most sensitive animals (Fig. 4). Because our criterion for masking threshold was extinction of $N_{1}$ it was expected that CAP tuning curve thresholds and CAP thresholds at $20 \mathrm{kHz}$ would be similar. This was found to be the case; Tuning curve and CAP thresholds averaged within $1.5 \pm 5.6 \mathrm{~dB}$ of each other. The loss of hearing sensitivity with age was accompanied by a reduction in sharpness of tuning. The tips of CAP tuning curves became blunted, while tails remained little affected (Fig. 3C, Fig 4). These changes appeared to correlate with threshold increases, more than aging per se. Comparison of Figures 2 and 4 shows that most animals older than $\sim 6$ mos had thresholds at $20 \mathrm{kHz}$ above 30 dB SPL and CAPTCs with $Q_{20 s}<4.0$. 

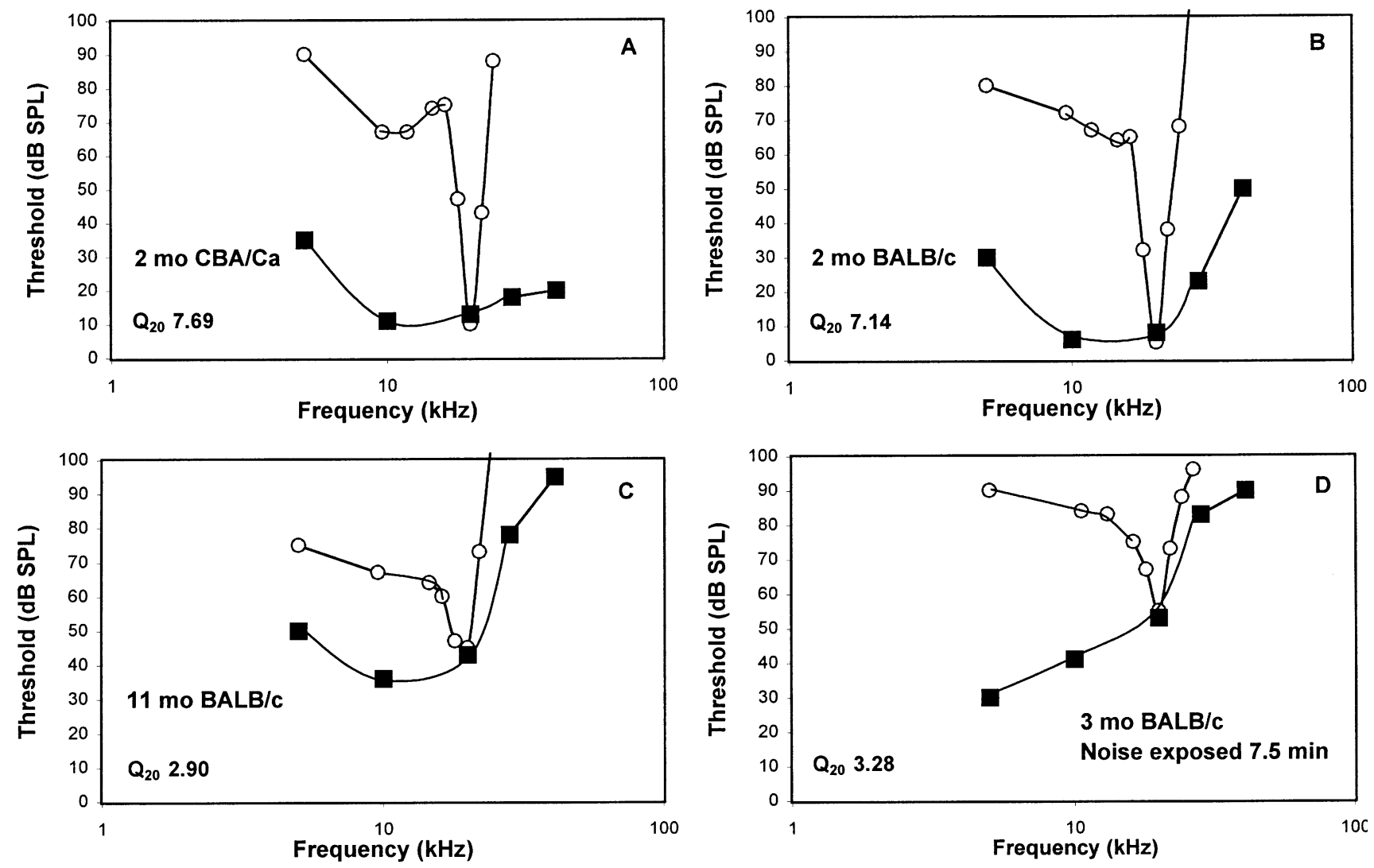

FIG. 3. Example CAP thresholds $(\mathbf{\square})$ and CAP tuning curves $(O)$ in four animals. A. Young CBA/Ca comparison. B. Young BALB/C. C. Aging BALB/c. D. Young BALB/c exposed to broadband noise.

Effects of noise on sensitivity and frequency tuning

Even a relatively brief (7.5 min) exposure to broadband noise at $110 \mathrm{~dB}$ SPL led to substantial threshold elevations. Similar to aging, these shifts were most pronounced at high frequencies (Fig. 5). The effects of NIHL on CAPTCs were also similar to those of aging (compare Fig. 3C with D): Tips of CAP tuning curves became blunted (Fig. 4), while tails were less affected. Among mice with thresholds at $20 \mathrm{kHz}$ above $50 \mathrm{~dB}$ SPL, only noise exposure yielded CAPTCs for which no $Q_{20}$ could be defined. Thus, for a given threshold elevation, noise exposure may be more disruptive of frequency tuning than is aging.

\section{Endocochlear potentials}

Endocochlear potentials obtained in the cochlear base for $\mathrm{BALB} / \mathrm{c}$ and comparison $\mathrm{CBA} / \mathrm{Ca}$ mice matched those from previous studies of mouse, both in "normal" mean and range (Steel and Barkway 1989; Cable et al. 1993). Potentials were narrowly distributed between 80 and $110 \mathrm{mV}$ and averaged

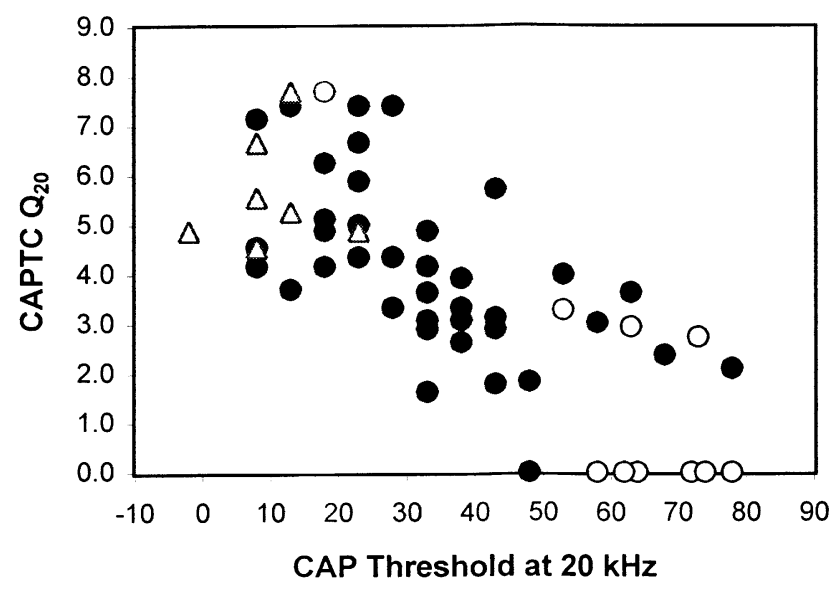

FIG. 4. Scatter plot of CAP tuning curve $Q_{20}$ versus CAP thresholds at $20 \mathrm{kHz}$ in BALB/c mice of various ages $(\mathbf{O})$, noise-exposed young $\mathrm{BALB} / \mathrm{c}$ mice $(\bigcirc)$, and comparison CBA/Ca mice $(\triangle) . Q_{20}$ in the most sensitive animals ranged $\sim 4.0-8.0$ but progressively decreased for thresholds above $\sim 30 \mathrm{~dB}$ SPL.

near $100 \mathrm{mV}$ regardless of age, noise history, or strain (Figs. 6 and 7). There was no indication of a relationship between CAP threshold at $20 \mathrm{kHz}$ and EP. 


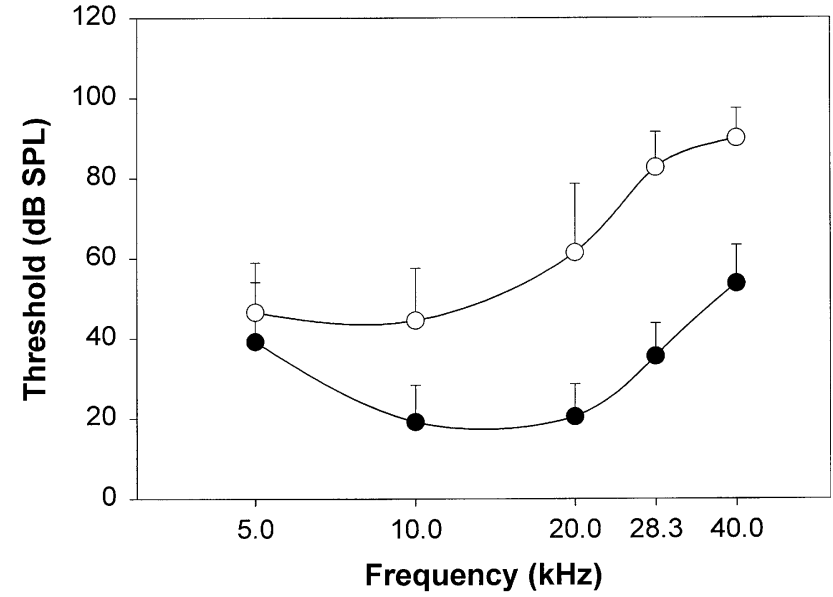

FIG. 5. Mean (+SD) CAP thresholds in young BALB/c mice $1.5-2.5$ mos) and in mice exposed to broadband noise $(\bigcirc)$ measured $2-3$ weeks following exposure.

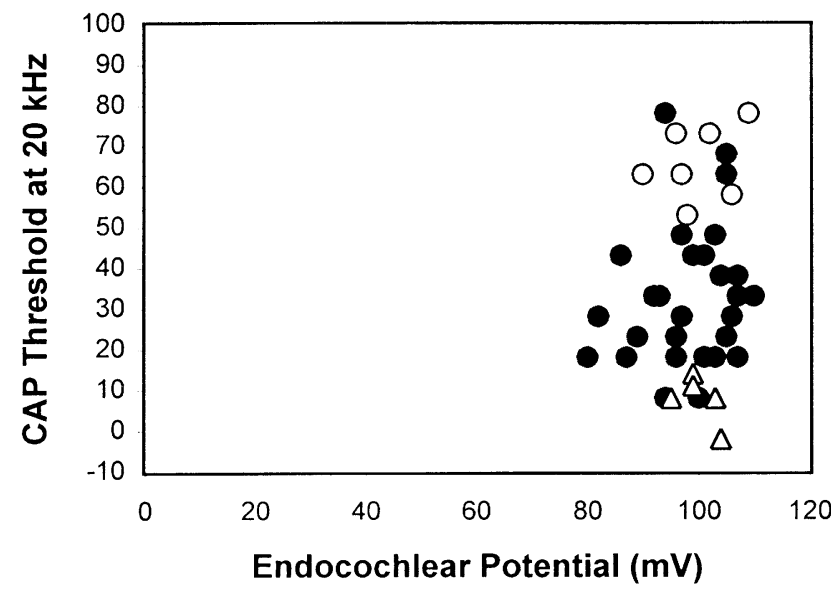

FIG. 6. Scatter plot of CAP thresholds at $20 \mathrm{kHz}$ versus endocochlear potentials in BALB/C mice of various ages $(\mathbf{)})$, noise-exposed young BALB/C mice $(\bigcirc)$, and comparison CBA/Ca mice $(\mathbf{O})$.

\section{Hair cell loss}

Hair cell counts were obtained in the $20 \mathrm{kHz}$ region of the cochlea for mice showing a highly contrasting CAP tuning curve $Q_{20}(<2.0$ and $>5.0)$ (Fig. 8). Sharp frequency tuning was invariably associated with normal outer hair cell density, based on previous data (Willott et al. 1998; Ohlemiller et al. 2000b). Identification of nine "low- $Q$ " animals suitable for counts (see Fig. 4) revealed six that were noise-exposed and three older than 7 mos. Whether poor frequency tuning was linked to decreased OHC density depended upon whether it was caused by aging or noise exposure. Reduction in $Q_{20}$ as a result of aging did not appear to involve outer hair cell loss (Fig. 8). By contrast, there was a significant loss of OHCs in the noise-exposed mice compared with controls (one-way ANOVA, $p<0.05)$, although pronounced loss oc-

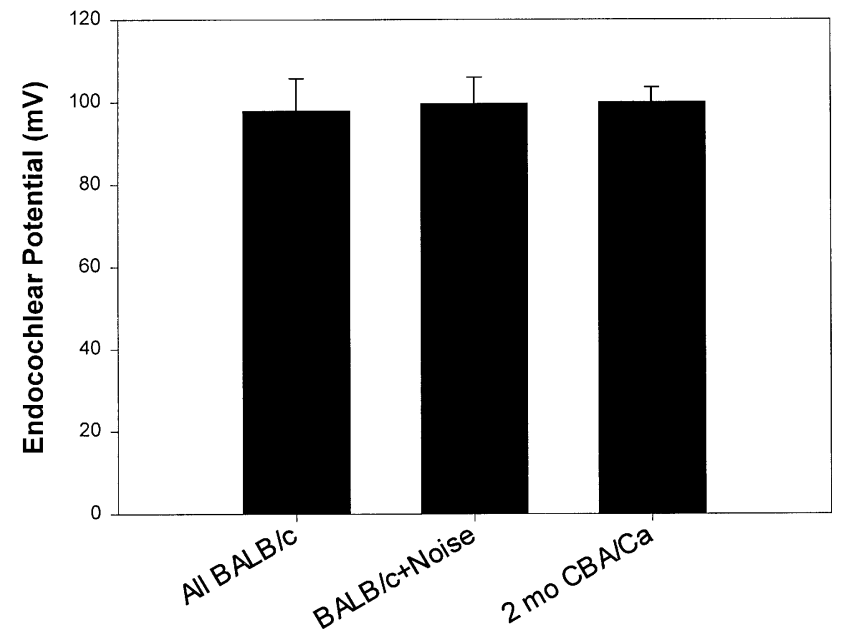

FIG. 7. Mean (+SD) endocochlear potential for BALB/c mice of various ages, noise-exposed young BALB/c mice, and comparison CBA/Ca mice. Differences were not significant (one-way ANOVA on ranks, $p=0.875)$.

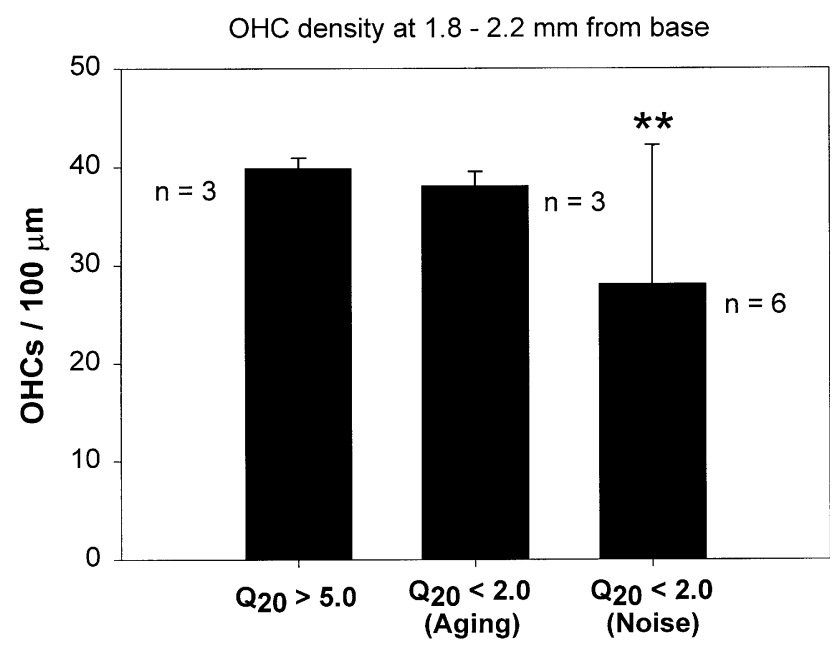

FIG. 8. Mean (+SD) outer hair cell density near the $20 \mathrm{kHz}$ region (1.8-2.2 $\mathrm{mm}$ from the base) of the right cochlea in BALB/c mice at opposite extremes of the $Q_{20}$ range $(<2.0$ and $>5.0)$. Counts were pooled (three counts per cochlea, nonoverlapping spans) by group. Noise-exposed animals showed significant hair cell loss compared with young controls (**one-way ANOVA on ranks, $p<0.05$ ).

curred in only three of the six exposed animals. Seven of the nine low- $Q$ animals, whether because of aging or noise, showed OHC loss within the most basal 1.5 $\mathrm{mm}$, that is, basal to the $20 \mathrm{kHz}$ region. Qualitative inspection indicated no OHC loss within the apical half of the cochlea, and no inner hair cell loss was noted in any region. While spiral ganglion cell counts were not attempted, examination of midmodiolar sections revealed loss and clumping of neuronal cell bodies with aging, particularly toward the basal and apical extremes. 


\section{Appearance of the lateral wall}

Stria vascularis and spiral ligament were examined in 13 animals, including 10 that showed threshold elevation and reduced sharpness of tuning from aging or noise exposure. Neither strial nor spiral ligament atrophy were noted in any of the animals. Figure 9 shows stria vascularis and spiral ligament (see also Fig. 11) in the lower basal turn of three typical cochleas at ages up to one year. No thinning, cell loss, or other changes are apparent. Normal EPs, recorded near the region shown, are shown for two of the animals (Fig. 9B, C). Taken together, anatomical and physiological findings indicate that strial and spiral ligament function in BALB/c mice are normal to at least 13 mos of age [by which time hearing loss is pronounced (Fig. 1)] and are unaffected by noise exposure sufficient to cause severe hearing loss.

\section{Organ of Corti in the $20 \mathrm{kHz}$ region}

The organ of Corti near the $20 \mathrm{kHz}$ region was examined by light microscopy in two normal control animals and in six animals with elevated thresholds and poor frequency tuning at $20 \mathrm{kHz}\left(Q_{20}<2.0\right)$. Four of these had been noise-exposed; the remaining two were greater than 10 months of age. Abnormalities were found in cochleas from all of the noiseexposed animals. In addition to variable outer hair cell loss, cellular correlates of noise injury included occasional vacuolated inner hair cells (Fig. 10A, thin arrow) and alterations in supporting cells. The latter included densely staining extracellular material adjacent to Boettcher's and Hensen's cells (Fig. 10A, thick arrow); dark staining and vacuolation of Hensen's cells, Boettcher's cell, and Deiters' cells (Fig. 10B, thick arrows); and possible buckling of pillar cells (Fig. 10B, arrowhead).

Cellular correlates of age-related changes in sensitivity and tuning were more difficult to identify than those for noise injury. One of the two aging cochleas examined in the $20 \mathrm{kHz}$ region showed a collapse of the reticular lamina lateral to the outer hair cells (Fig. 10C, arrow), while the other showed no clear pathology. To extend these observations, additional cochleas from four mice greater than 10 months old with $Q_{20}<3.0$ were examined in the midmodiolar section. Two of these showed abnormalities of supporting cells that extended into the upper basal turn. These were similar to those described for noise injury.

\section{Degeneration of spiral limbus}

Because threshold shifts at high frequencies as a result of noise and aging were often associated with relatively subtle anatomical changes, we expected that cellular correlates of threshold elevation in the apical half of the cochlea to be even more subtle. However, cochleas from noise-exposed mice exhibited dramatic differences in the appearance of the spiral limbus in the base versus midcochlear and apical regions. Figure 11 shows the upper basal turn (just within the apical half of the cochlea) from three young mice, two of which were noise-exposed (Fig. 11B, C). The spiral limbus, particularly the central zone of this structure, is essentially completely acellular in the noise-exposed animals. Interdental cells are largely preserved. In mice where this was seen, this acellularity was also nearly always present at more apical locations within the same section. Estimating that the upper basal region in these sections represents frequencies near $10 \mathrm{kHz}$ ( \pm 0.5 octave), we examined the relationship between the density of fibrocyte nuclei in the central zone of the limbus at this location and threshold sensitivity at $10 \mathrm{kHz}$. To extend this analysis, we included 10 noise-exposed BALB/c mice from a previous study (Ohlemiller et al. 2000b) for which pre-and postexposure sensitivity data and midmodiolar sections were available. As shown in Figure 12, noise-exposed animals with thresholds at $10 \mathrm{kHz}$ above $40 \mathrm{~dB}$ SPL exhibited a severely degenerated limbus with virtually no fibrocytes in the central zone. Animals undergoing more mild noise exposures, and which showed near-normal thresholds at $10 \mathrm{kHz}$, showed consistently higher cell density in the limbal central zone. Degeneration of limbus fibrocytes was not limited to BALB/c mice nor to mice carrying the Ahl mutation. Examination of archival material from noise-exposed C57BL/6 and CBA/Ca mice (not shown) revealed similar trends.

Figure 12 also shows that mice whose thresholds were elevated from aging alone did not undergo reduction in limbus fibrocyte density within the upper base. However, it was possible to observe changes in the limbus with age. Figure 13 shows the apical cochlear region from three aging mice. As in Figure 11, the central zone of the limbus is degenerated to varying degrees, indicated by decreased density of fibrocyte nuclei, while interdental cells are mostly spared. Some degree of degeneration of the apical limbus was observed in five of six mice aged 10-13 mos.

\section{DISCUSSION}

Normal and abnormal frequency tuning in mice

Based on the $20 \mathrm{kHz}$ region, BALB/c and CBA/Ca mice possess comparable frequency tuning up to the age when BALB/c thresholds exceed $\sim 30 \mathrm{~dB}$ SPL. Comparison of CAPTCs of young versus aging and noise-exposed mice indicated that noise injury and aging exert similar effects on frequency tuning in the 


\section{Lower Base}
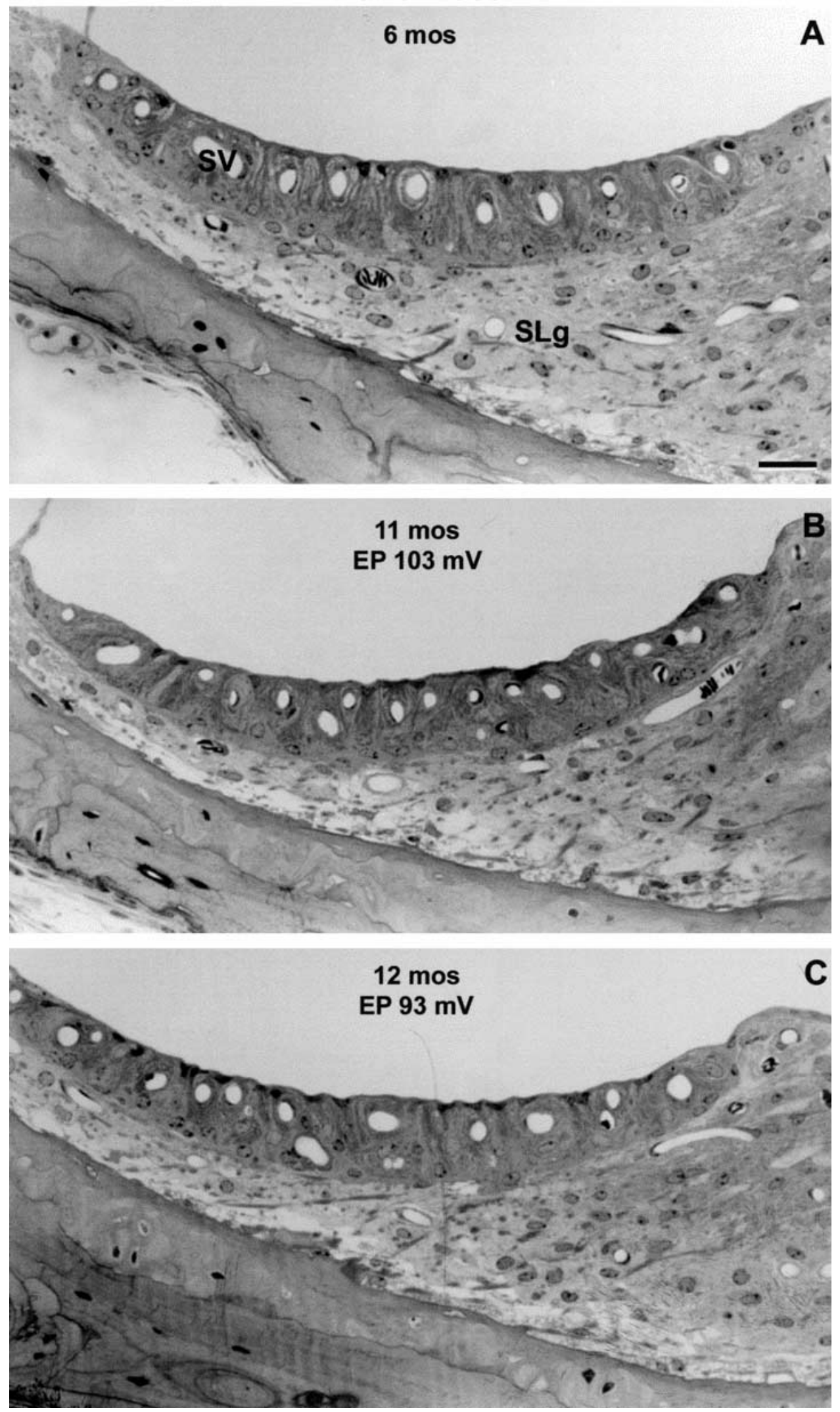

FIG. 9. Light photomicrographs of $2.0 \mu \mathrm{m}$ midmodiolar sections showing stria vascularis and spiral ligament in the lower basal turn of BALB/C mice at three ages. SV: stria vascularis; SLg: spiral ligament. Scale bar $=22 \mu \mathrm{m}$. 


\section{0 kHz Region}

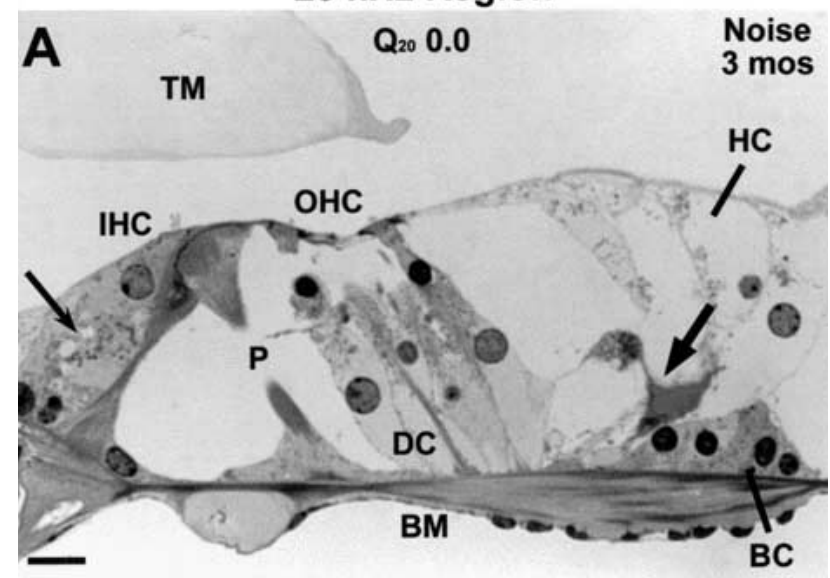

B

\section{$Q_{20} 0.0$}

Noise
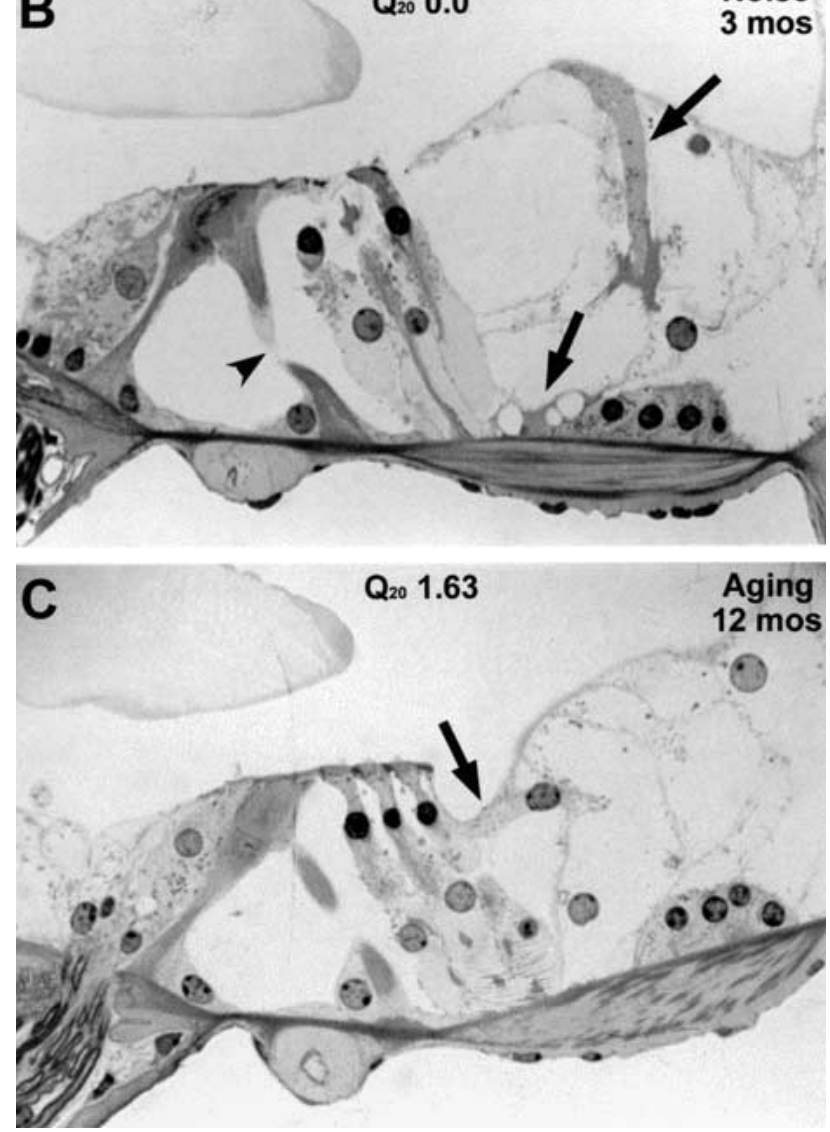

FIG. 10. Light photomicrographs of $1.0 \mu \mathrm{m}$ radial sections showing the organ of Corti near the $20 \mathrm{kHz}$ region of right cochleas taken from noise-exposed $(\mathbf{A}, \mathbf{B})$ and aging $(\mathbf{C})$ BALB/c mice. Thin arrow $(\mathbf{A})$ shows vacuolated inner hair cell. Thick arrows in $\mathbf{A}$ and $\mathbf{B}$ show anomalies of Hensen's and Boettcher's cells. Arrowhead (B) indicates buckled pillar cell. Arrow in $\mathbf{C}$ shows collapse of reticular lamina. TM: tectorial membrane; IHC: inner hair cell; OHC: outer hair cell; BM: basilar membrane; P: pillar cell; DC: Deiters' cells; HC: Hensen's cells; BC: Boettcher's cells. Scale bar $=11 \mu \mathrm{m}$.

\section{Upper Base}
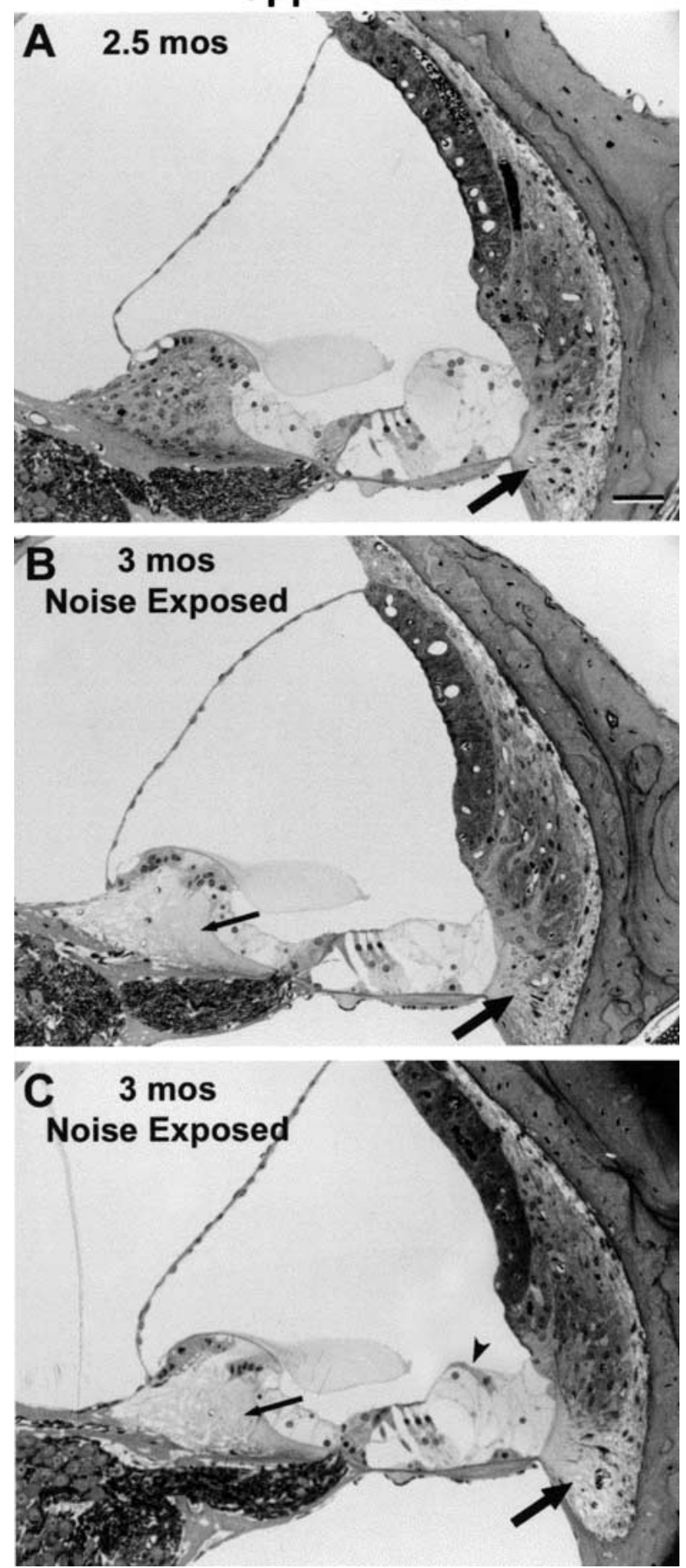

FIG. 11. Light photomicrographs of $2.0 \mu \mathrm{m}$ midmodiolar sections from scala media in the cochlear upper base taken from a young BALB/C mouse and two similar-aged mice that were noise-exposed. Note loss of cellularity within spiral limbus (thin arrow in B, C). Arrowhead in C indicates injured Hensen's or tectal cell. Spiral ligament appears normal (thick arrows). Scale bar $=44 \mu \mathrm{m}$. 


\section{Cellular correlates of noise and aging in mice}

Noise. As of the present study, nearly every type of permanent noise injury that has been reported in any mammal has been found in mice, including hair cell loss (Yoshida et al. 1999; Ohlemiller et al. 2000a; Ou et al. 2000a; Yoshida et al. 2000), stereocilia damage (Yoshida et al. 1999; Ou et al. 2000a), secondary nerve fiber degeneration (Ou et al. 2000a), and alterations in supporting cells (present study). The majority of studies indicate that noise injury to the stria vascularis is uncommon for all but the most severe exposures (Ward and Duvall 1971; Duvall et al. 1974; Bohne and Clark 1982). Our data support the same conclusion in the mouse.

Noise-induced degeneration of the mouse spiral limbus, also recently reported by others (Node and Adams 2001; Wang and Liberman 2001), has been observed in guinea pigs (Covell 1953) and cats (Liberman and Kiang 1978). Cross-species similarities include a predominantly apical occurrence and the sparing of interdental cells (Mangabeira-Albernaz 1961; Kimura et al. 1990). Also common is the finding that degeneration of the limbus is not attended by obvious changes in the organ of Corti. The appearance of limbus degeneration in the apical cochlea, while the largest threshold shifts and most obvious degenerative changes in the organ of Corti are in the base, suggests that the cellular targets of noise differ between the cochlear base and apex. It remains to be determined whether changes in the limbus account for noise-induced threshold shifts at lower frequencies in mice and by what mechanism. In general, these have been more difficult to explain in cellular terms than threshold shifts at high frequencies (Ou et al. 2000a).

Aging. The cells and structures affected by aging appeared to be the same as those affected by broadband noise. It was primarily the spatial extent of outer hair cell loss, alterations in supporting cells, and degeneration of spiral limbus that differentiated noise and aging in our animals. Age-related abnormalities in supporting cells extended more apically than did hair cell loss and were suggestive of an ongoing process. Supporting cell pathology may first impact hearing sensitivity by altering the mechanical or ionic environment of hair cells and then promote hair cell loss. Age-related changes in the spiral limbus were limited to more apical regions than those associated with broadband noise exposure. It remains to be determined if they extend basally with increasing age. Cell loss in spiral limbus was apparent not only in BALB/cJ mice, but also in our archival material from older CBA/CaJ mice. It therefore is not unique to Ahl. Schuknecht also described age-related changes in limbus (Schuknecht 1974; Schuknecht et al. 1974) and included it among the features of sensory ARHL.

\section{Mouse $A h l$ as a model for human ARHL}

The murine $A h l$ locus is much studied for clues it may offer regarding the genetics and cellular processes underlying ARHL. Since mice that carry the same allele typically show hearing loss early in adulthood, long before they are "old," the premise of such research is that $A h l$ accelerates cochlear degeneration that should also be observable in some aging mice. In C57BL/ 6 and BALB/c mice, Ahl also imparts susceptibility to noise injury (Henry 1982; Li 1992a; Erway et al. 1996; Ohlemiller et al. 2000b; Davis et al. 2001; Jimenez et al. 2001). This suggests that it accelerates a general aging-like process that is exquisitely sensitive to genetic and environmental interplay. Consistent with this is our observation of rough equivalence between the anatomical correlates of noise exposure and aging and recent reports that $A h l$ impacts the hearing phenotype associated with at least three other loci (Johnson et al. 2001; Zheng and Johnson 2001; Kozel et al. 2002). Schuknecht also noted the similarity and possibility of overlap between the histopathology of noise injury and sensory ARHL (Schuknecht 1974; Schuknecht and Gacek 1993), so that some ARHL categories, or subsets of these, may represent cumulative injury. All published reports to date implicate $A h l$ in pathology of some combination of organ of Corti, spiral ganglion, spiral ligament, stria vascularis, and spiral limbus. Schuknecht observed age-related degeneration of all of these, and collectively they span all of his ARHL categories. Thus, Ahl apparently promotes forms of mixed ARHL. It should be noted, however, that Schuknecht's criteria required that hearing ability be affected by a given type of cell loss before a classification was made. Even moderate degeneration of spiral ganglion, spiral ligament, or stria was considered unlikely to impact sensitivity. It is not clear how relevant such criteria are to comparisons between humans and animal models. Work with gerbils suggests that only 60 $70 \%$ of stria vascularis need to function normally for the EP and hearing sensitivity to fall within normal limits (Schulte and Schmiedt 1992). Schuknecht's criteria for strial ARHL therefore appear reasonable for animals also.

The features of Ahl-related pathology are well studied only in C57BL/ 6 and BALB/c mice. Information thus remains limited about the "core" attributes of $A h l$ (i.e., those traits least subject to genetic modification). Ahl has been implicated in degeneration of the stria vascularis and spiral ligament in C57BL/6 and related strains (Mikaelian 1979; Ichimiya et al. 2000; Hequembourg and Liberman 2001). Where these have been observed, they appear modest and may not contribute to hearing loss (Schuknecht 1974; Schulte and 
Schmiedt 1992). By contrast, BALB/c mice exhibit normal appearance and function of stria and spiral ligament (as indicated by a normal EP) up to 13 months of age. The relationship between $A h l$ and degeneration of the lateral wall may therefore be indirect and readily subject to modification by other loci in the genetic background.

\section{ACKNOWLEDGMENTS}

This work is dedicated to the career and character of Norma Slepecky. We thank Jaci Lett and Patty Lear for technical assistance and Barbara Bohne for comments on the manuscript. Supported by the Edward Mallinckrodt, Jr. Foundation and NIH R01 DC03454 (KKO).

\section{REFERENCES}

Bohne BA, CLARK WW. Growth of hearing loss and cochlear lesion with increasing duration of noise exposure. In: Hamernik RP, Henderson D, Salvi R (eds) New Perspectives on Noise-Induced Hearing Loss, New York, Raven Press, pp 283-302, (1982).

BRown CJ, ABBAs PJ. A comparison of AP and ABR tuning curves in the guinea pig. Hear. Res. 25:193-204, (1987).

Bryda EC, Kim HJ, Legare me, Frankel WN, Noben-Trauth K. High-resolution genetic and physical mapping of Modifier-ofDeafwaddler $(m d f w)$ and Waltzer $\left(C d h 23^{v}\right)$. Genomics 73:338342, (2001).

Cable J, Jackson IJ, Steel KP. Light $\left(\mathrm{B}^{1 \mathrm{t}}\right)$, a mutation that causes melanocyte death, affects stria vascularis function, in the mouse inner ear. Pigment Cell Res. 6:215-225, (1993).

Covell WP. Histologic changes in the organ of Corti with intense sound. J. Comp. Neurol. 99:43-59, (1953).

Dallos P, Cheatham MA. Compound action potential (AP) tuning curves. J. Acoust. Soc. Am. 59:591-597, (1976).

Dallos P, Cheatham MA. Analog of two-tone suppression in wholenerve responses. J. Acoust. Soc. Am. 62:1048-1051, (1977).

Davis RR, Newlander JK, Ling XB, Cortopassi GA, Kreig EF, Erway LC. Genetic basis for susceptibility to noise-induced hearing loss in mice. Hear. Res. 155:82-90, (2001).

Di Palma F, Holme RH, Bryda EC, Belyantseva IA, Pellegrino R, Kachar B, Steel KP, Noben-Trauth K. Mutations in Cdh23, encoding a new type of cadherin, cause stereocilia disorganization in waltzer, the mouse model for Usher syndrome type ID. Nat. Genet. 27:103-107, (2001).

Dolan TG, Mills JH, Schmiedt RA. A comparison of brainstem, whole-nerve AP and single-fiber tuning curves in the gerbil: Normative data. Hear. Res. 17:259-266, (1985).

Duvall AJ, WARD WD, LAuHALA KE. Stria ultrastructure and vessel transport in acoustic trauma. Ann. Otol. Rhinol. Laryngol. 83:498-514, (1974).

Erway LC, Shiau YW, Davis RR, Kreig EF. Genetics of age-related hearing loss in mice. III. Susceptibility of inbred and Fl hybrid strains to noise-induced hearing loss. Hear. Res. 93:181-187, (1996).

Erway LC, Willott JF, Archer JR, Harrison DE. Genetics of agerelated hearing loss in mice: I. Inbred and Fl hybrid strains. Hear. Res. 65:125-132, (1993).

Evans EF. The frequency response and other properties of single fibers in the guinea-pig cochlear nerve. J. Physiol. 226:263-287, (1972).
Geisler CD, Rhode WS, Kennedy DT. Responses to tonal stimuli of single auditory nerve fibers, and their relationship to basilar membrane motion in the squirrel monkey. J. Neurophysiol. 37:1156-1172, (1974).

HARRIS DM. Action potential suppression, tuning curves and thresholds: Comparison with single fiber data. Hear. Res. 1:133154, (1979).

Harrison RV, Aran JM, Erre JP. AP tuning curves from normal and pathological human and guinea pig cochleas. J. Acoust. Soc. Am. 69:1374-1385, (1981).

HENRY KR. Influence of genotype and age on noise-induced auditory losses. Behav. Genet. 12:563-573, (1982).

Henry KR. Ageing and audition. In: Willot JF (ed) The auditory psychobiology of the mouse. Springfield, IL, Charles C. Thomas, pp. 470-494, (1983).

HenRY KR. Tuning of the auditory brainstem OFF responses is complementary to tuning of the auditory brainstem ON response. Hear. Res. 19:115-125, (1985).

Henry KR, McGinn MD, Carter LA, Savoska EA. Auditory brainstem function of the Fl offspring of the cross of CBA/CaJ and AU/SsJ mice. Audiology 31:190-195, (1992).

Hequembourg S, Liberman MC. Spiral ligament pathology: A major aspect of age-related cochlear degeneration in C57BL/6 mice. J. Assoc. Res. Otolaryngol. 2:118-129, (2001).

IChimiya I, Suzuki M, Goro M. Age-related changes in the murine cochlear lateral wall. Hear. Res. 139:116-122, (2000).

Jimenez AM, Stagner BB, Martin GK, Lonsbury-Martin BL. Agerelated loss of distortion product otoacoustic emissions in four mouse strains. Hear. Res. 138:91-105, (1999).

Jimenez AM, Stagner BB, Martin GK, Lonsbury-Martin BL. Susceptibility of DPOAEs to sound overexposure in inbred mice with AHL. J. Assoc. Res. Otolaryngol. 2:233-245, (2001).

Johnson KR, ERway LC, CoOK SA, Willott JF, Zheng QY. A major gene affecting age-related hearing loss in C57BL/6J mice. Hear. Res. 114:83-92, (1997).

Johnson KR, Zheng QY, BykhovskaYa Y, Spirina O, Fischel-GhoDSIAN N. A nuclear-mitochondrial DNA interaction affecting hearing impairment in mice. Nat. Genet. 27:191-194, (2001).

Johnson KR, Zheng QY, ERWAY LC. A major gene affecting agerelated hearing loss is common to at least 10 inbred strains of mice. Genomics 70:171-180, (2000).

Kiang NYS, Watanabe T, Thomas EC, Clark LF. Discharge Patterns of Single Fibers in the Cat's Auditory Nerve. Cambridge, MA, MIT Press, (1965).

Kimura RS, Nye CL, Southard RE. Normal and pathologic features of the limbus spiralis and its functional significance. Am. J. Otolaryngol. 11:99-111, (1990).

Kozel PJ, Davis RR, Kreig EF, Schull GE, Erway LC. Deficiency in plasma membrane calcium ATPase isoform 2 increases susceptibility to noise-induced hearing loss in mice. Hear. Res. (in press), (2002).

LI HS. Influence of genotype and age on acute acoustic trauma and recovery in $\mathrm{CBA} / \mathrm{Ca}$ and $\mathrm{C} 57 \mathrm{BL} / 6 \mathrm{~J}$ mice. Acta Otolaryngol. 112:956-967, (1992a).

Li HS. Genetic influences on susceptibility of the auditory system to aging and environmental factors. Scand. Audiol. Suppl. 36: 1-39, (1992b).

Li HS, Hultcrantz M. Age-related degeneration of the organ of corti in two genotypes of mice. ORL J. Otorhinolaryngol. Relat. Spec. 56:61-67, (1994).

Liberman MC, KIANg NYS. Acoustic trauma in cats: Cochlear pathology and auditory nerve activity. Acta Otolaryngol. 358:1-63, (1978).

Mangabeira-Albernaz PL. Histochemistry of the connective tissue of the cochlea. Laryngoscope 71:1-18, (1961).

Mikaelian DO. The development and degeneration of hearing in the C57/b16 mouse: Relation of the electrophysiologic 
responses from the round window to cochlear anatomy and behavioral responses. Laryngoscope 89:1-15, (1979).

National Center for Health Statistics. Prevalence and characteristics of persons with hearing trouble. Department of Health and Human Services, Public Health Service, Washington, DC, (1994).

Node M, AdAms JC. Effects of acoustic trauma in non-sensory cochlear cells. Abstr. Assoc. Res. Otolaryngol. 24:147, (2001).

Ohlemiller KK, McFadden SL, Ding DL, Lear PM, Ho YS. Targeted mutation of the gene for cellular glutathione peroxidase $(G p x l)$ increases noise-induced hearing loss in mice. J. Assoc. Res. Otolaryngol. 1:243-254, (2000a).

Ohlemiller KK, McFadden SL, Ding DL, Reaume AG, Hoffman EK, Scott RW, Wright JS, Putcha GV, Salvi RJ. Targeted deletion of the cytosolic $\mathrm{Cu} / \mathrm{Zn}$-Superoxide Dismutase gene (SOD1) increases susceptibility to noise-induced hearing loss. Audiol. Neuro. Otol. 4:237-246, (1999).

Ohlemiller KK, Siegel JH. Cochlear basal and apical differences reflected in the effects of cooling on responses of single auditory nerve fibers. Hear. Res. 80: 174-190, (1994).

Ohlemiller KK, Wright JS, Heidbreder AF. Vulnerability to noiseinduced hearing loss in 'middle-aged' and young adult mice: A dose-response approach in CBA, C57BL, and BALB inbred strains. Hear. Res. 149:239-247, (2000b).

Ou HC, Bohne BA, Harding GW. Noise damage in the C57BL/CBA mouse cochlea. Hear. Res. 145:111-122, (2000a).

Ou HC, Harding GW, Bohne BA. An anatomically based frequency-place map for the mouse cochlea. Hear. Res. 145:123129, (2000b).

Parham K. Distortion product otoacoustic emissions in the C57BL/ $6 \mathrm{~J}$ mouse model of age-related hearing loss. Hear. Res. 112:216234, (1997).

Saitoh Y, Hosokawa M, Shimada A, Watanabe Y, Yasuda N, Murakami Y, Takeda T. Age-related cochlear degeneration in senescence-accelerated mouse. Neurobiol Aging. 16:129-136, 1995.

Saitoh Y, Hosokawa M, Shimada A, Watanabe Y, Yasuda N, MuraKAMI Y, TAKedA T. Age-related hearing impairment in Senescence-accelerated mouse (S\&M). Hear. Res. 75:27-37, 1994.

Saitoh Y, Hosokawa M, Shimada A, Watanabe Y, Yasuda N, Takeda T, accelerated mouse (SAM). Hear. Res. 75:27-37, (1994).

Salvi R, Perry J, Hamernik RP, Henderson D. Relationships between cochlear pathologies and auditory nerve and behavioral responses following acoustic trauma. In: Hamernik RP, Henderson D, Salvi R, (eds), New Perspectives in Noise-induced Hearing Loss. New York, Raven Press, pp. 165-188, (1982).

SAUNDERs JC, Dolgin KG, Lowry LD. The maturation of frequency selectivity in C57BL/6J mice studied with auditory evoked response tuning curves. Brain Res. 187:69-79, (1980).

Saunders JC, Garfinkle TJ. Peripheral anatomy and physiology I. In: Willott JF, (ed) The auditory psychobiology of the mouse. Springerfield, IL, Charles C. Thomas, pp. 131-168, (1983).

Schmiedt RA, Zwislocki JJ, HAMERnik RP. Effects of hair cell lesions on responses of cochlear nerve fibers. I. Lesions, tuning curves, two-tone inhibition, and responses to trapezoidal wave patterns. J. Neurophysiol. 43:1367-1389, (1980).

SCHUKNEChT HF. Pathology of the Ear. Cambridge, MA, Harvard University Press, (1974).

Schuknecht HF, GaceK MR. Cochlear pathology in presbycusis. Ann. Otol. Rhinol. Laryngol. 102:1-16, (1993).

Schuknecht HF, Watanuki K, Takahashi T, Belal AA, Kimura RS, Jones DD. Atrophy of the stria vascularis, a common cause for hearing loss. Laryngoscope 84:1777-1821, (1974).

Schulte BA, Schmiedt RA. Lateral wall $\mathrm{Na}^{+}, \mathrm{K}^{+}$-ATPase and endocochlear potentials decline with age in quiet-reared gerbils. Hear. Res. 61:35-46, (1992).

Spongr VP, Flood DG, Frisina RD, SAlvi RJ. Quantitative measures of hair cell loss in CBA and C57BL/ 6 mice throughout their life span. J. Acoust. Soc. Am. 101:3546-3553, (1997).

StEEL KP. Inherited hearing defects in mice. Ann. Rev. Genet. 29:675-701, (1995).

SteEl KP, Barkway C. Another role for melanocytes: their importance for normal stria vascularis development in the mammalian inner ear. Development 107:453-463, (1989).

Walsh EJ, McGee J. Hypothyroidism in the Tshr mutant mouse. In: Willott JF (ed) Handbook of Mouse Auditory Research: From Behavior to Molecular Biology. New York, CRC Press, pp. 537555, (2001).

WANG Y, Liberman MC. Time course of noise-induced cellular damage and repair in the mouse cochlea. Abstr. Assoc. Res. Otolaryngol. 24:147, (2001).

WARD WD, Duvall AJ. Behavioral and ultrastructural correlates of acoustic trauma. Ann. Otol. Rhinol. Laryngol. 80:881-896, (1971).

Willott JF (1991). Aging and the Auditory System: Anatomy, physiology, and psychophysics. Singular Publishing Group, San Diego.

Willott JF, Turner JG, Carlson S, Ding D, Bross LS, Falls Wa. The BALB/c mouse as an animal model for progressive sensorineural hearing loss. Hear. Res. 115:162-174, (1998).

Wilson SM, Householder DB, Coppola V, Tessarollo L, Fritzsch B, Lee EC, Goss D, Carlson GA, Copeland NG, Jenkins NA. Mutations in Cdh23 cause nonsyndromic hearing loss in waltzer mice. Genomics 74:228-233, (2001).

Yoshida N, Hequembourg SJ, Atencio CA, Rosowski JJ, Liberman MC. Acoustic injury in mice: $129 / \mathrm{SvEv}$ is exceptionally resistant to noise-induced hearing loss. Hear. Res. 141:97-106, (2000).

Yoshida N, Kristiansen A, Liberman MC. Heat stress and protection from permanent acoustic injury in mice. J. Neurosci. 19:1011610124, (1999).

Zheng QY, Johnson KH, ERwAY LC. Assessment of hearing in 80 inbred strains of mice by ABR threshold analysis. Hear. Res. 130:94-107, (1999).

ZHENG QY, JoHnson KR. Hearing loss associated with the modifier of deaf waddler ( $m d f w$ ) locus corresponds with age-related hearing loss in 12 inbred strains of mice. Hear. Res. 154:45-53, (2001) 